\title{
Translation Strategies of Traditional Chinese Medicine Terms from the Perspective of Cross-Culture Communication
}

\author{
Na Zhang, Mei Dong \\ Xi'an Shiyou University, Xi'an, China \\ Email:719473514@qq.com
}

How to cite this paper: Zhang, N. and Dong, M. (2020) Translation Strategies of Traditional Chinese Medicine Terms from the Perspective of Cross-Culture Communication. Open Access Library Journal, 7: e6828.

https://doi.org/10.4236/oalib.1106828

Received: September 16, 2020

Accepted: October 13, 2020

Published: October 16, 2020

Copyright $\odot 2020$ by author(s) and Open Access Library Inc.

This work is licensed under the Creative

Commons Attribution International

License (CC BY 4.0).

http://creativecommons.org/licenses/by/4.0/

\section{(c) $\underset{\mathrm{By}}{\mathrm{By}}$ Open Access}

\begin{abstract}
As an indispensable part of traditional Chinese culture, Traditional Chinese Medicine (TCM) is extensive and profound. Driven by globalization, Traditional Chinese Medicine has gradually stepped onto the international stage and attracted extensive attention worldwide. From the perspective of crossculture communication, this paper will focus on English translation strategies of TCM terms.
\end{abstract}

\section{Subject Areas}

Linguistics

\section{Keywords}

Traditional Chinese Medicine Terms, Translation, Culture, Strategy

\section{Introduction}

\subsection{The Necessity of Spreading Traditional Chinese Medicine Culture}

Traditional Chinese Medicine is the quintessence of China. Traditional Chinese Medicine (TCM) is an indispensable part of Chinese classical culture. With its extensive and profound culture and long history, the Traditional Chinese Medicine has drawn great attention across the world. It has walked into people's life and boosted the development of human health. The spread of TCM culture is related to the construction of China's soft power and the great strategy of "going out" of Chinese culture, which is conducive to cultural integration between TCM and the world. 
Globalization has created opportunities for the communication of TCM and Chinese culture. Under the influence of globalization, a variety of foreign cultures have sprung up along the trend, which has also brought broad-ranging and significant effects for Chinese traditional culture. Under such circumstances, Chinese traditional culture followed the trend and gradually went global. Globalization has provided good conditions for the spread of Traditional Chinese Medicine culture as well. At the same time, the "TCM fever" that has emerged in recent years continues to rise globally, laying a foundation for TCM to enter the international world.

Traditional Chinese Medicine is the treasure of the Chinese nation and the cultural essence of the Chinese people for thousands of years. In the ancient China, after thousands of years of clinical practice, traditional Chinese medicine has saved countless lives. And now it is highly expected to save more people in the world not only Chinese people. So, TCM shouldered its responsibility to serve the people worldwide. It aimed to make contributions to human health and reduce the pain in this world.

\subsection{The Difficulty of Spreading Traditional Chinese Medicine Culture}

The spread of TCM culture cannot be separated from translation activities. Translation is not only cross-linguistic communication, but also a cross-culture communication activity, dealing with two language systems under different cultural backgrounds. (Zhang, X., Shi, Y. Z., 2008, P. 941-944) [1] While in the process of translation, the most difficult part is to translate the TCM terms accurately and help the readers fully understand Chinese culture which is partly reflected by TCM terms.

Traditional Chinese medicine is the essence of Traditional Chinese culture and philosophy. After thousands of years, it has been deeply rooted in ancient Chinese traditional culture and imprinted with the Chinese culture and national conditions. Therefore, cultural factors must be considered in TCM translation. At the same time, in the process of cross-cultural communication, to help the readers to better understand TCM, the translator should consider the cultural factors of the target country while preserving Chinese cultural characteristics, so as to avoid cultural conflicts. To weaken the strangeness and improve the effect of cross-cultural communication is part of translators' mission. For example, in the translation of TCM terms “青龙汤” and “白虎汤”, if they are directly translated as "Blue Dragon Decoction" and "White Tiger Decoction", foreign readers will be puzzled, and they may even mistake this decoction in making from animal organs. In the West, people pay great attention to the protection of animal rights and interests, and the relationship between human and animals is very harmonious. We cannot imagine what will happen if we translate the terms literally. It will greatly damage China's national image and hinder the world's correct understanding of Traditional Chinese Medicine. At the same time, in the eyes of westerners, the dragon is a symbol of violence and evil, while in the eyes 
of Chinese people, the dragon represents auspiciousness and power, which is extremely sacred and symbolizes Chinese culture and national spirits. Therefore, the cultural differences between China and foreign countries must be taken into account when translating such terms with special cultural connotations. On one hand, the connotation of Chinese culture should be preserved; on the other hand, the effectiveness of cross-cultural TCM communication should be promoted. The translators should make a balance between all elements. For example, “青龙汤” can be translated as Qinglong Tang (the decoction for treating external cold and internal fluid), and “白虎汤” can be translated as Baihu Tang (the decoction for clearing away heat from Qifen) (Li, Y. A., P. 792-793) [2].

\section{Characteristics of TCM Terminology}

Terms of Traditional Chinese Medicine (TCM) were formed in ancient China, some of which have a history of thousands of years and have profound cultural connotation. The characteristics of TCM terms are mainly reflected in the following aspects:

\subsection{The Historical Features of TCM Terms}

Due to the Traditional Chinese Medicine history, the terminology is mostly ancient Chinese, sometimes the characters are words, such as “气”, and sometimes the short sentences can also be regarded as a word, such as “木克土”, “肺主气”, “心开窍于舌” and so on (Tang, R., 2015, P. 21-22) [3].

\subsection{Humanistic Features of TCM Terms}

Traditional Chinese Medicine (TCM) is a discipline based on biology, integrated with physics, chemistry, mathematics and other disciplines, and permeated with humanistic philosophy. Its profound influence on ancient medicine is directly reflected in its terminologies (Tang, R., 2015, P. 21-22) [3]. For example, the term "yin and yang" comes from the theory of yin and yang, an ancient Chinese philosophical thought.

\subsection{Qualitative Description of TCM Terms}

Wheezing, wheezing of deficiency type, cold wheezing, hot wheezing etc. are rarely described quantitatively (Tang, R., 2015, P. 21-22) [3].

\subsection{Its Abstract Concepts are Expressed in Concrete Nouns}

Such as the “五行 (five elements)" 金, 木, 水, 火, 土 are expressed by words such as gold, wood, water, fire, earth. 木生火, 火生土, 火克金 can be described by wood generating, fire generating, fire restraining. (Zhu, J. P., 2006, P. 6) [4].

\subsection{Metaphorical Characteristics}

There are a lot of metaphorical terms in TCM field, such as 舌苔 (fur of tongue), 命门 (life gate), 血海 (blood sea), 涌泉 (gushing spring), etc. 


\subsection{Plenty of Polysemous Terms}

Polysemy is another distinctive feature of TCM terms. It is frequently used in TCM. There are still some polysemous terms with unknown meanings, and the translation of these terms has not been decided yet. For example, the term "血. 室” in traditional Chinese Medicine, generally refers to liver, thoroughfare vessel, and uterus, while we can hardly find the polysemy in western medicine.

\section{Translation Strategies of TCM Terms from the Perspective of Cross-Culture Communication}

Based on the characteristics of TCM terms and the original intention of spreading TCM culture, the author believes that we should be flexible in translating TCM terms and adopt different translation strategies for different terms.

\subsection{Foreignization and Domestication Strategies}

The concepts of "foreignization" and "domestication" were first put forward by Lawrence Venuti, an American translation theorist. "Foreignization" translation emphasizes that the characteristics and connotations of the source language should be retained as much as possible in the language form and content of the target language, so as to maximize the cultural heterogeneity of the source language. "Domestication" emphasizes the dominant role of the target language, and the processing of the target language should be subject to the linguistic characteristics and cultural needs of the target language, so as to increase the readability of the translation, but make the target readers unable to understand the foreign culture (Wang, Z. Y, Cheng, Y., 2016, P. 7) [5].

\subsection{Translation Methods of TCM Terms under the Guidance of Foreignization Strategy}

\subsubsection{Literal Translation Method}

Literal translation can keep the style and meaning of the original text as much as possible, and it is the best choice when the sentence pattern and content are relatively consistent (Zhang, Q. R., Song, H. Y., 2011, P. 80-82) [6]. In Traditional Chinese Medicine, if there is a direct equivalent term in the target language, literal translation can be adopted. Such as 心, 肺 肝, 胆, 脾, their corresponding English words are heart, lung, liver, gall, spleen.

\subsubsection{Transliterating Method}

Under the influence of ancient Chinese culture, the unique linguistic phenomenon in the language of TCM has led to many "cultural gaps" in the translation of TCM terms. Transliteration can be used to solve these gaps (Tang, R., 2015, P. 146) [3]. For some traditional Chinese medicine terms with strong ethnic culture, if literal translation or free translation cannot accurately convey their cultural connotation, the original term's cultural connotation can be faithfully conveyed through transliteration. Terms such as "yin and yang", "qi" and "massage" have typical traditional Chinese cultural characteristics. Whether literal transla- 
tion or free translation, they cannot accurately convey the connotation of the original text. At this time, it is better to use Pinyin translation. If such terms appear for the first time, it is necessary to give explanatory notes so that the readers can better understand the text. For example, WHO International Standard Terminologies on Traditional Medicine in the Western Pacific Region issued in 2007 adopts transliteration and annotation to help readers fully understand the terms (Li, Z. G., 2017, P. 6) [7]. For example, term “阴阳” was explained in this way: yin and yang-the general descriptive terms for the two opposites, complementary and inner-related cosmic forces found in all matter in nature. The ceaseless motion of both yin and yang gives rise to all changes seen in the world.

\subsubsection{Transliteration Combination Method}

It seems quite difficult to find the related terms in target language when translating TCM terms to express some abstract concepts. In this case, free translation for a specific part can be a good choice to help readers better understand the content. While for the abstract part, we can use transliteration to retain its cultural connotation and characteristics. For example, the term “阴阳消长” can be translated into “waxing and waning of yin and yang”. Another example “先天之 气”: innate qi, 阴证: yin syndrome, 元气: original qi, 泻白散: xiebai powder. Similarly, when such terms first appear, they also require explanatory notes.

\subsection{Translation Methods of TCM Terms under the Guidance of Domestication Strategy}

\subsubsection{Free Translation Method}

In the process of TCM communication, on the one hand, the native culture should be preserved and translated in a practical way; on the other hand, the receptive ability of the target language readers should also be taken into consideration. Therefore, domestication strategies should be appropriately adopted to help the target language readers better understand the source language.

Free translation refers to the translation method that gives up the form and style of the original text to express the real meaning of the original text. We can also say that free translation is a supplement to literal translation (Peng, C. L., 2014, P. 4) [8].

For example, the word “戌风”, in Chinese medicine, refers to the evil wind formed by the abnormal weather in four seasons, while if translated literally as "thief wind", it will be confusing and unintelligible. And if translated as "pathogenic wind”, it will be easy to understand. Another term, “乌风内障” describes lesions to the eye that cause cataracts. If we translate it into "black wind interior barrier", it would be completely confusing for target readers to understand the terms. However, “glaucoma” is the best translation. Similarly, “白虎历节” abandoning its literal translation, can be translated into "acute arthritis".

\subsubsection{Amplification Translation Method}

Amplification translation method is an important way to convey the original meaning of the text, which should also be used in the translation of TCM terms. 
Most TCM terms are characterized by using lots of ancient Chinese characters which contain more information such as history, culture, origin and the development. If we just translate the meaning and neglect the culture backgrounds, the transcript will lose its original meaning. Therefore, amplification method are widely used in Chinese-English translation, including the translation of TCM terms. For example, the TCM term “水之上源”, can be translated into “upper source of water", and we can add the information in brackets (an expression referring to the lung, which is situated in the upper energizer regulating water metabolism). On one hand, it conveys the hidden meaning of the term, on the other hand, it helps the reader well understand the term. In a word, amplification translation method can be adopted in the translation of TCM terms.

\section{Conclusion}

Traditional Chinese Medicine is a treasure of the Chinese nation and carries a long history and culture. Under the background of globalization, the spread of TCM culture is conducive to promoting TCM, TCM culture and Chinese culture to the world. At the same time, TCM also shoulders the mission of benefiting the whole mankind. On the basis of understanding the differences in language, culture and way of thinking between China and the West, translators should choose appropriate translation strategies and methods to accurately translate TCM terms with Chinese characteristics to foreign readers, so as to accelerate the internationalization of TCM and make it better benefit the people of the whole world as soon as possible.

\section{Acknowledgements}

I would like to express my gratitude to all those who helped me during the writing of this paper. My deepest gratitude goes first and foremost to professor Dong Mei, who led me into the world of translation. Without her constant encouragement and guidance, I could not have finished this paper smoothly.

My thanks would also go to my beloved family for their understanding and great support. I also owe my sincere gratitude to my friends and my classmates, especially my roommates, who gave me their help so that I could work out my problems during the difficult course of this paper.

\section{Conflicts of Interest}

The authors declare no conflicts of interest regarding the publication of this paper.

\section{References}

[1] 张璇, 施蕴中. 《黄帝内经》常用文化负载词英译[J]. 中西医结合, 2008, 28(10): 941-944.

[2] 李永安. 音译在中医名词翻译中的应用[J]. 中国中西医结合, 2001(10): 792-793.

[3] 唐韧. 中医跨文化传播: 中医术语翻译的修辞和语言挑战 $[\mathrm{M}]$. 北京: 科学出版 
社, 2015.

[4] 朱建平. 中医术语规范化与中医现代化国际化 [J]. 中华中医药杂志, 2006(1): 6-8.

[5] 王中雨, 程颜. 从异化与归化看中医属术语[J]. 中医药信息, 2016(4): 71-73.

[6] 张庆荣, 宋海英. 直译〉异化 意译〉归化 “和而不同”一一中医药英语翻译的辩证 思考 [J]. 江苏中医药, 2011, 43(4): 80-82.

[7] 李照国. 中医基本名词术语英译研究 $[M]$. 西安: 世界图书出版公司, 2017: 6 .

[8] 彭昌柳. 文化翻译理论指导下的中医术语英译策略研究[J]. 湖北第二师范学院学 报, 2014, 31(4): 120-122. 